\title{
A point prevalence study of 150 patients with idiopathic retinal vasculitis: 2 . Clinical relevance of antiretinal autoimmunity and circulating immune complexes
}

\author{
EVA KASP, ' ELIZABETH M GRAHAM, ${ }^{2}$ M R STANFORD,' M D SANDERS, \\ AND D C DUMONDE'
}

From the Departments of 'Immunology and ${ }^{2}$ Medical Ophthalmology, United Medical and Dental Schools of Guy's and St Thomas's Hospitals, St Thomas's Campus, London SE1 7EH

SUMMARY This study describes the occurrence of antiretinal antibodies and circulating immune complexes in the sera of a large series of patients with idiopathic retinal vasculitis whose ophthalmological and clinical features are presented in Part 1. Antiretinal antibodies were measured by indirect immunofluorescence and passive haemagglutination, and circulating immune complexes were measured by polyethylene glycol precipitation and Clq binding. The occurrence of antiretinal antibodies and that of circulating immune complexes were analysed in relation to each other, to severity of retinal disease, to the type of associated systemic inflammatory disease, and to the presence of individual features of retinal inflammation. In patients with retinal vasculitis together with systemic inflammatory disease circulating immune complexes were usually accompanied by antiretinal antibodies. However, those patients with antiretinal antibodies in the absence of circulating immune complexes tended to have more severe retinal vasculitis, a feature particularly evident in Behçet's disease $(\mathrm{p}=0.028)$. In patients with isolated retinal vasculitis, severity of disease was associated with antiretinal antibody $(p=0.013)$, as well as with the occurrence of both antiretinal antibody and circulating immune complexes together $(p=0 \cdot 010)$. In the series as a whole there was a tendency for individual features of retinal vasculitis to be associated with antiretinal antibodies unaccompanied by circulating immune complexes; especially in macular oedema $(p=0 \cdot 028)$. In isolated retinal vasculitis there was also an additive effect of antiretinal antibodies and circulating immune complexes in relation to disease severity; in contrast, in patients with systemic inflammatory disease, the coexistence of antiretinal antibodies and circulating immune complexes was associated with less severe retinal inflammation $(\mathrm{p}=0 \cdot 014)$. It is concluded that both antiretinal autoimmunity and circulating immune complexes may act as immunopathogenetic factors in idiopathic retinal vasculitis but that, in certain patients, circulating immune complex formation seems to protect against the more severe forms of autoimmune retinal inflammatory disease.

The eye was the first organ in which inflammation was ascribed to immunopathological mechanisms, ${ }^{1}$ yet after eighty years the pathogenesis of much ocular inflammatory disease remains ill understood. ${ }^{2}$ However, there is growing evidence that idiopathic retinal Correspondence to Dr E Kasp, Department of Immunology, Rayne Institute, St Thomas's Hospital, London SE1 7EH vasculitis is in fact immunologically mediated; for though this may occur in isolation, the disease is frequently associated with systemic inflammatory disorders in which the immune system is known to be abnormal, ${ }^{2}$ and in either situation retinal inflammation may respond to immunosuppressive therapy. ${ }^{3}$ Moreover, experimental models of uveoretinitis can 
be produced by autosensitisation with retinal proteins, and previous work has pointed to associations between circulating immune complexes and antiretinal autoimmunity in the human disease. ${ }^{+11}$

In the preceding paper we describe in detail the ophthalmological features of 150 patients with idiopathic retinal vasculitis, 83 of whom had concomitant systemic inflammatory disease. In this paper we report on the occurrence of antiretinal antibodies and circulating immune complexes in this large group of patients. The study was undertaken to extend our earlier findings in a smaller group of patients ${ }^{6}$ and to clarify whether these immunological criteria would discriminate patients with isolated retinal vasculitis (RV) from those with retinal vasculitis accompanying systemic inflammatory disease (RV+SID). An additional objective was to determine whether these immunological criteria, singly or together, would reflect the associated systemic disease or the form and severity of retinal inflammation.

\section{Materials and methods}

\section{PATIENTS}

Of the 150 patients described in the preceding paper ${ }^{3}$ a complete study of antiretinal antibodies (ret-AB) and circulating immune complexes (CIC) was obtainable in 142. Of these, two categories were specified: 63 patients had isolated retinal vasculitis (RV) and the remaining 79 had retinal vasculitis in association with systemic inflammatory disease (RV+SID). The latter category consisted of 38 patients with Behçet's disease (RV+Behçet's) and 14 patients with sarcoidosis (RV+sarcoid); the remaining 27 patients had other inflammatory diseases (RV+other SIDs), which included 11 with neurological abnormalities ('uveomeningitis group') and nine with seronegative polyarthritis, of which five were HLA B27-positive. ${ }^{3}$

\section{MEASUREMENT OF ANTIRETINAL ANTIBODIES}

Two methods were used: passive haemagglutination (Hagg) and indirect immunofluorescence (IIF). In the passive haemagglutination test bovine retinal-Santigen " was coupled to sheep erythrocytes with the aid of chromium chloride.? Serial dilutions of patients' sera, in $20 \mu \mathrm{l}$ volumes, were incubated in microtitre plates with equal volumes of $1 \% \mathrm{~S}$-antigen coated red cells for two hours at room temperature, and the degree of haemagglutination was scored on a 4-point scale of + to ++++ . Antibody titre was expressed as the highest serum dilution giving definite $(+)$ agglutination. In the indirect immunofluoresence test cryostat sections of snap frozen human retina were used as substrate. The tissue specificity of antiretinal immunofluorescence was established by reference to a standard polyclonal guineapig anti- serum, raised against bovine S-antigen. Retinalspecific immunofluorescence was given by the photoreceptor layers of cones and rods, the cytoplasm of the outer nuclear layer, and the outer plexiform layer. A series of 57 sera from healthy control laboratory staff were examined by passive haemagglutination and by indirect immunofluorescence for the presence of antiretinal antibodies. By haemagglutination 53 of these sera had a titre of $\leqslant 1: 8$, and by immunofluorescence 50 were negative at a dilution of 1:5. Accordingly, the patients' sera were regarded as positive for antiretinal antibodies when these gave either a titre of $\geqslant 1: 32$ by haemagglutination or a titre of $\geqslant 1: 10$ by immunofluorescence.

MEASUREMENT OF CIRCULATING IMMUNE COMPLEXES

Two methods were used: a polyethylene glycol (PEG) precipitation test and a Clq solid phase radiometric assay. In the PEG test the serum was precipitated with $2 \%$ polyethylene glycol and the IgG content of the precipitate was evaluated by radial immunodiffusion. ${ }^{12}$ The Clq binding test was done by a modification of the method of Hay et al..$^{13}$ Appropriately diluted sera were incubated in tubes coated with human Clq; immune complex levels were determined by subsequent reactivity with a ${ }^{125}$ I-labelled antiglobulin reagent, and the test was calibrated with aggregated human IgG. Our modification comprised the preincubation of Clq-coated tubes with nonlabelled rabbit antihuman IgG $(\mathrm{Fc} \gamma)$, which helped to reduce the background uptake of labelled antiglobulin and to minimise false negative results in sera containing rheumatoid factors. Both PEG and Clq tests were validated in selected patients with renal, rheumatic, and haematological diseases, and in a large panel of healthy subjects. The following ranges of normal values were obtained: Clq-CIC, 20.6 (SD 2.6) $\mathrm{mg} \mathrm{IgG/l} \mathrm{of} \mathrm{serum;} \mathrm{and} \mathrm{PEG-CIC,} 25$ (SD 12) mg $\mathrm{IgG} / \mathrm{l}$ of serum. CIC levels were deemed to be raised when the results were more than 2 SD above the normal mean: that is, when either the Clq test gave a value in excess of $25.8 \mathrm{mg} \mathrm{IgG/l}$ or the PEG test gave a value exceeding $49 \mathrm{mg} \mathrm{IgG} / \mathrm{l}$.

\section{STATISTICAL ANALYSIS OF THE DATA}

All clinical and immunological data were entered into a computer. Patients in the two major categories ( $R V$ alone, $R V+S I D)$, or in the three groups with concomitant systemic disease, or displaying defined ophthalmological criteria, were selected for comparative analysis of immunological and clinical features. Data were analysed by means of the Student's $t$ test or by constructing $2 \times 2$ contingency tables and calculating $\chi^{2}$ and $p$ values to evaluate the significance of associations between respective features. 
Fig. 1 Prevalence of antiretinal antibodies in the two patient categories as detected by indirect immunofluoresence (IIF titre $\geqslant 1: 10$ ) or passive haemagglutination (Hagg titre $\geqslant 1: 32$ ).

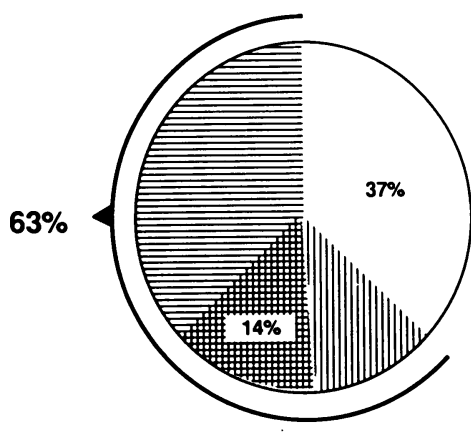

RV + SID

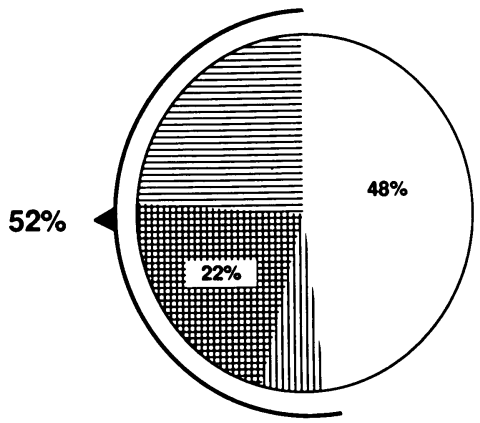

RV alone

\section{Results}

PREVALENCE OF ANTIRETINAL AUTOIMMUNITY

The sera of 83 patients $(58 \%)$ were found to have antiretinal antibodies as measured by either passive haemagglutination (titres $\geqslant 1: 32$ ) or indirect immunofluorescence (titres $\geqslant 1: 10$ ). Fig. 1 shows that by these criteria (see 'Methods') antiretinal antibodies were more prevalent in the sera of patients with $\mathrm{RV}+\mathrm{SID}(63 \%)$ than those with $\mathrm{RV}$ alone $(52 \%)$, but that in the latter category there were more patients whose sera were positive in both tests $(22 \%)$ than in the RV+SID category $(14 \%)$. Of the 57 normal sera also examined one gave a haemagglutination titre of $\geqslant 1: 32$ and a second was positive by immunofluorescence at a dilution of $1: 10$. In this study the prevalence of antiretinal antibodies in

Table 1 Prevalence of raised levels of circulating immune complexes $(\mathrm{CIC})$ in the sera of two categories of patients with idiopathic retinal vasculitis

\begin{tabular}{|c|c|c|c|c|}
\hline \multirow[b]{2}{*}{$\begin{array}{l}\text { Category of } \\
\text { patients }\end{array}$} & \multirow[b]{2}{*}{$\begin{array}{l}\text { CIC-positive } \\
\text { sera* }\end{array}$} & \multicolumn{3}{|c|}{$\begin{array}{l}\text { Proportion of CIC-positive } \\
\text { sera reacting in: }\end{array}$} \\
\hline & & $\begin{array}{l}\text { Clq } \\
\text { binding } \\
\text { test }\end{array}$ & $\begin{array}{l}P E G \\
\text { precipitation } \\
\text { test }\end{array}$ & $\begin{array}{l}\text { Both Clq and } \\
\text { PEG tests } \\
\text { together }\end{array}$ \\
\hline $\begin{array}{l}\text { RV alone } \\
\text { (63 patients) } \\
\text { RV+SID } \\
\text { ( } 79 \text { patients) }\end{array}$ & $\begin{array}{l}25(40 \%) \\
31(39 \%)\end{array}$ & $\begin{array}{l}19 / 25 \\
(76 \%) \\
20 / 31 \\
(65 \%)\end{array}$ & $\begin{array}{l}8 / 25 \\
(32 \%) \\
14 / 31 \\
(45 \%)\end{array}$ & $\begin{array}{l}2 / 25 \\
(8 \%) \\
3 / 31 \\
(10 \%)\end{array}$ \\
\hline
\end{tabular}

${ }^{*}$ CIC-positive sera were defined as those giving positive values in either the Clq or the PEG test (see 'Methods') normal sera was accordingly taken as 2/57 (i.e. $3 \cdot 5 \%$ ).

PREVALENCE OF RAISED LEVELS OF CIRCULATING IMMUNE COMPLEXES

The sera of 56 patients $(39 \%)$ were found to have raised levels of $\mathrm{CIC}$ as measured by either Clq binding or PEG precipitation. Raised CIC levels were equally distributed between the two patient categories: RV alone, 25/63 (40\%); and RV+SID, $31 / 79(39 \%)$. Table 1 shows that the majority of CICpositive sera were detected by the Clq binding test: in patients with RV alone these comprised $76 \%$ of all CIC-positive sera, while the respective figure for the $\mathrm{RV}+\mathrm{SID}$ category was $65 \%$. Immune complexes detected by the PEG method were less prevalent in both patient categories ( $\mathrm{RV}$ alone, 32\%; RV+SID,

Table 2 Prevalence of antiretinal antibodies and raised levels of circulating immune complexes in different patient groups

\begin{tabular}{|c|c|c|c|c|}
\hline \multirow[b]{2}{*}{$\begin{array}{l}\text { Patient } \\
\text { group } \\
\text { (and no.) }\end{array}$} & & \multicolumn{3}{|c|}{ Prevalence of immunological abnormalities } \\
\hline & & $\begin{array}{l}\text { Antiretinal } \\
\text { antibodies }\end{array}$ & $\begin{array}{l}\text { Raised } \\
\text { CIC }\end{array}$ & $\begin{array}{l}\text { Both } \\
\text { antiretinal } \\
\text { antibodies } \\
\text { and raised } \\
\text { CIC }\end{array}$ \\
\hline RV alone & (63) & $33(52 \%)$ & $25(40 \%)$ & $14(22 \%)$ \\
\hline RV + Behçet's & (38) & $21(55 \%)$ & $12(32 \%)$ & $9(24 \%)$ \\
\hline $\begin{array}{l}\text { RV + sarcoid } \\
\text { RV + other }\end{array}$ & $(14)$ & $10(71 \%)$ & $6(43 \%)$ & $4(29 \%)$ \\
\hline SIDS & (27) & $19(70 \%)$ & $13(48 \%)$ & $11(41 \%)$ \\
\hline All patients & (142) & $83(58 \%)$ & $56(39 \%)$ & $38(25 \%)$ \\
\hline
\end{tabular}


Table 3 Prevalence of antiretinal antibodies in the two patient categories in relation to their circulating immune complex (CIC) status

\begin{tabular}{llllll}
\hline & \multicolumn{3}{l}{ Prevalence of antiretinal antibodies } & \\
\cline { 2 - 5 } $\begin{array}{l}\text { Patient } \\
\text { category }\end{array}$ & $\begin{array}{l}\text { in CIC. } \\
\text { positive } \\
\text { sera }\end{array}$ & $\begin{array}{l}\text { in CIC- } \\
\text { negative } \\
\text { sera }\end{array}$ & $\begin{array}{l}\text { Significance } \\
\text { of difference } \\
(p \text { value })\end{array}$ \\
\hline All patients & $38 / 56$ & 68 & $45 / 86$ & 52 & $0 .(156$ \\
RV alone & $14 / 25$ & 56 & $19 / 38$ & 50 & $>0 \cdot 5$ \\
RV+SID & $24 / 31$ & 77 & $26 / 48$ & 54 & $0 \cdot(136$ \\
\hline
\end{tabular}

$45 \%)$. It was of interest that few sera $(8-10 \%)$ gave positive results in both CIC tests (Table 1).

PREVALENCE OF ANTIRETINAL ANTIBODIES AND CIRCULATING IMMUNE COMPLEXES IN DIFFERENT PATIENT GROUPS

Table 2 displays the prevalence of and association between antiretinal antibodies and raised levels of $\mathrm{CIC}$ in patients with $\mathrm{RV}$ alone and in the three groups of the RV+SID category: RV+Behçet's disease, $\mathrm{RV}+$ sarcoid, and $\mathrm{RV}+$ other SIDs. There was a similar proportion of patients with antiretinal antibodies in the RV alone $(52 \%)$ and RV+Behçet's disease $(55 \%)$ groups, while the rest of the patients with systemic inflammatory disease had a higher incidence of antiretinal antibodies (70-71\%). Raised levels of CIC were found in the sera of $39 \%$ of all patients and in $40 \%$ of those with RV alone. There were, however, some variations in the prevalence of
CIC within the RV+SID category of patients. Thus, raised $\mathrm{CIC}$ were found in $32 \%$ of sera of patients with $\mathrm{RV}+$ Behçet's disease, in $43 \%$ of the RV+sarcoid group, and $48 \%$ of the group with RV + other SIDs.

Table 3 and Fig. 2 show associations between antiretinal antibodies and raised levels of CIC in the total patient population, in the two major patient categories, and in the individual groups of the $\mathrm{RV}+\mathrm{SID}$ category. When all patients were considered, $68 \%$ of those with raised levels of CIC also had antiretinal antibodies, while only $52 \%$ of the patients with normal CIC levels were antibody-positive $(p=0.066)$. In the RV+SID category $77 \%$ of CICpositive patients had antiretinal antibodies, while only $54 \%$ of CIC negative patients did so $(p=0.036)$. In contrast, in patients with RV alone antiretinal antibodies were equally prevalent in patients with raised $(56 \%)$ and normal $(50 \%)$ levels of CIC (Table 3 ). In all patient groups the proportion of positive sera reactive only for antiretinal antibodies was greater than the proportion of positive sera reactive only for circulating immune complexes (Fig. 2). Thus in $\mathrm{RV}$ alone, of the 33 antibody-positive patients 19 $(58 \%)$ were CIC-negative, while of the 25 CICpositive patients $11(44 \%)$ were antibody-negative; and this pattern was reflected in the other patient groups (Fig. 2). However, the proportion of sera within each patient group that contained both antiretinal antibodies and CIC together was similar (22$29 \%$ ) with the exception of the RV group associated with SIDs other than sarcoid or Behçet's disease, where it was somewhat higher ( $41 \%$ : Table 2$)$.

\section{Percentage positive sera reactive for $A B$ or $C I C$ only}

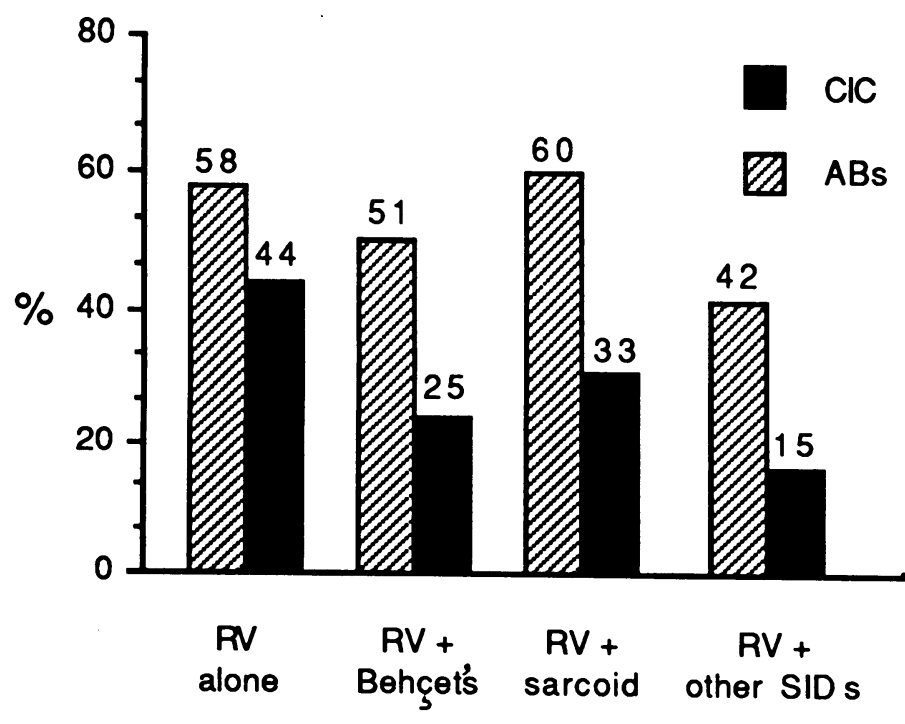

Fig. 2 Respective proportions of antibody-positive and CIC-positive sera in the different patient groups that expressed antiretinal antibodies only (hatched bars) or circulating immune complexes only (solid bars). 
Table 4 Prevalence of antiretinal antibodies in relation to CIC status and disease score in the two patient categories

\begin{tabular}{|c|c|c|c|c|}
\hline \multirow[b]{2}{*}{$\begin{array}{l}\text { Patient } \\
\text { category }\end{array}$} & \multirow[b]{2}{*}{$\begin{array}{l}\text { Retinal } \\
\text { disease } \\
\text { score }\end{array}$} & \multicolumn{3}{|c|}{ Prevalence of antiretinal antibodies } \\
\hline & & in all sera & $\begin{array}{l}\text { in CIC } \\
\text { positive } \\
\text { sera }\end{array}$ & $\begin{array}{l}\text { in CIC } \\
\text { negative } \\
\text { sera }\end{array}$ \\
\hline RV alone & $\begin{array}{l}\text { low }(\leqslant 10) \\
\text { high }(>10)\end{array}$ & $\begin{array}{l}11 / 30(37 \%)^{*} \\
22 / 33(67 \%)^{*}\end{array}$ & $\begin{array}{r}3 / 11(27 \%) \dagger \\
* 11 / 14(79 \%) \dagger\end{array}$ & $\begin{array}{r}8 / 19(42 \%) \\
11 / 19(58 \%)\end{array}$ \\
\hline RV+SID & $\begin{array}{l}\text { low }(\leqslant 10) \\
\text { high }(>10)\end{array}$ & $\begin{array}{l}28 / 42(67 \%) \\
22 / 37(59 \%)\end{array}$ & $\begin{array}{r}15 / 19(79 \%) \\
9 / 12(75 \%)\end{array}$ & $\begin{array}{l}13 / 23(56 \%) \\
13 / 25(52 \%)\end{array}$ \\
\hline
\end{tabular}

${ }^{*} \mathrm{p}=0 \cdot 013 . \dagger \mathrm{p}=0 \cdot 010$.

\section{ASSOCIATION BETWEEN DISEASE SEVERITY AND IMMUNOLOGICAL STATUS}

The severity of retinal inflammation was graded by means of a points system in which ophthalmological features were assigned a value according to their considered impact on visual morbidity. ${ }^{\circ}$ The total number of points for both eyes of each patient was recorded, and retinal disease severity was classified, firstly, as either 'low score' (1-10 points) or 'high score' (>10 points). The prevalence of $\mathrm{CIC}$ and retinal antibodies, either separately or in association with each other, was compared in patients with high and low disease scores, in the two categories RV alone and RV+SID. Table 4 shows that, in RV alone, there was a higher prevalence of antiretinal antibodies in patients with higher $(67 \%)$ rather than lower $(37 \%)$ disease scores $(p=0 \cdot 013)$. This was particularly evident in patients who also had raised CIC levels $(p=0 \cdot 010)$. In contrast, in the $R V+S I D$ patient category there was no overall association between disease severity and the prevalence of antiretinal antibodies: the prevalence of antiretinal antibodies was slightly lower (59\%) in patients with a high disease score than in those with a low disease score $(67 \%)$. Moreover, RV+SID patients with raised CIC levels tended to have antiretinal antibodies, whether they had high or low disease scores (Table 4).

The question arose whether antiretinal antibodies and CIC might act together in the pathogenesis of retinal vasculitis. Fig. 3 shows the proportion of patients with a high disease score showing antiretinal antibodies only, circulating immune complexes only, or the two immunological abnormalities together. In $\mathrm{RV}$ alone the majority of patients displaying both immunological abnormalities belonged to the highscore category $(11 / 14 ; 79 \%)$, while in $\mathrm{RV}+\mathrm{SID}$ a relative minority $(9 / 24: 38 \%)$ of such patients had high-score disease $\left(\chi^{2}=5.98 ; p=0 \cdot 014\right)$. Fig. 3 also demonstrates that the prevalence of patients with a high disease score in the RV alone category, who had both $\mathrm{CIC}$ and antiretinal antibodies together, bore an additive relationship to those with either CIC or antiretinal antibodies alone. In contrast, the prevalence of patients with a high disease score in the $\mathrm{RV}+\mathrm{SID}$ category who had both immunological abnormalities together was actually lower than in those who had either CIC or antiretinal antibodies alone.

Patients in both categories were then analysed by criteria of disease group, mean disease score (DS), and 'severe' retinal disease ( $>20$ points). Of the 78
Fig. 3 Respective proportions of patients with high disease scores (>10 points) in RV alone (solid bars) and $R V+S I D$ (hatched bars) whose sera contained either circulating immune complexes (CIC) only, antiretinal antibodies $(A B s)$ only, or CIC and $A B s$ together.

\section{Percentage of patients with high disease score}

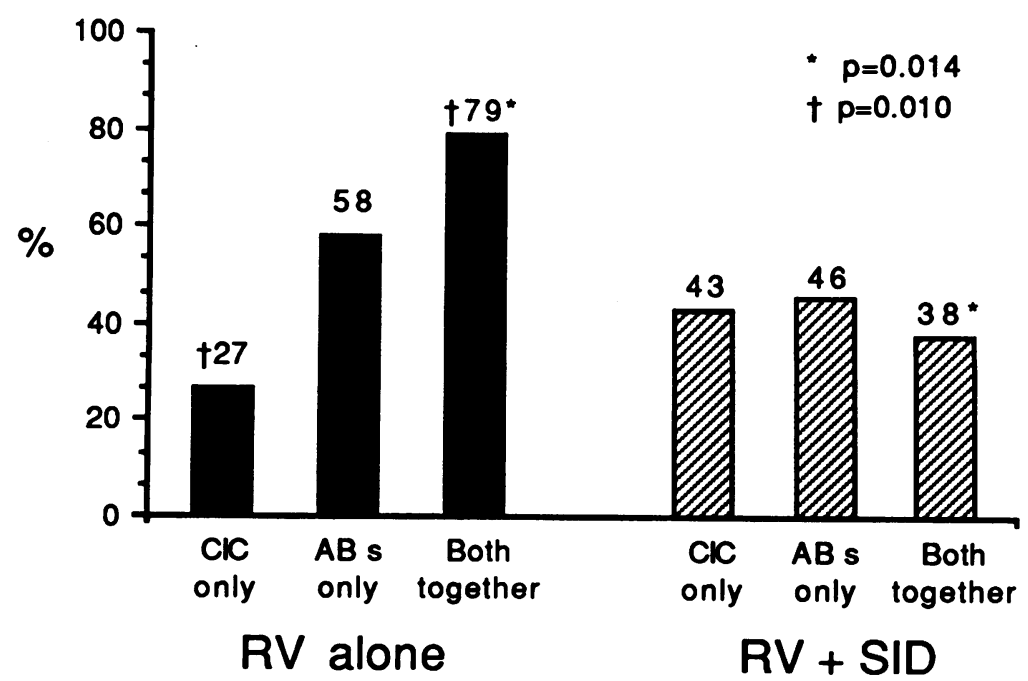


Table 5 Relationship between disease severity, antiretinal antibodies, and presence of circulating immune complexes in retinal vasculitis accompanying Behçet's, Sarcoidosis, and other systemic inflammatory disease

\begin{tabular}{lllll}
\hline $\begin{array}{l}\text { Patient group and disease } \\
\text { score }(D S)\end{array}$ & \multicolumn{2}{c}{ Antiretinal antibodies present } & Antiretinal \\
\cline { 2 - 5 } & Totals & CIC positive & CIC negative & antibodies absemt \\
\hline$R V+$ Behçet's: & 21 & 9 & 12 & 17 \\
DS $>20$ points & $8 / 21$ & $1 / 9 *$ & $7 / 12 *$ & $5 / 17$ \\
Mean DS (SEM) & $16 \cdot 1(2 \cdot 1)$ & $11 \cdot 9(2 \cdot 7)$ & $17 \cdot 9(2 \cdot 9)$ & $17 \cdot 1(2 \cdot 3)$ \\
$R V+$ sarcoid: & 10 & 4 & 6 & 4 \\
DS $>20$ points & $1 / 10$ & $0 / 4$ & $1 / 6$ & $0 / 4$ \\
Mean DS (SEM) & $12 \cdot 2(4 \cdot 0)$ & $8 \cdot 5(1 \cdot 9)$ & $14 \cdot 7(7 \cdot 3)$ & $9 \cdot 2(2 \cdot 5)$ \\
$R V+$ other SID: & 19 & 11 & 8 & 8 \\
DS $>20$ points & $3 / 19$ & $2 / 11$ & $1 / 8$ & $0 / 8$ \\
Mean DS (SEM) & $9 \cdot 8(2 \cdot 0)$ & $9 \cdot 1(2 \cdot 9)$ & $11 \cdot 3(3 \cdot 4)$ & $6 \cdot 3(1 \cdot 7)$ \\
\hline
\end{tabular}

*Behçet's+severe RV, antibody positive:

$\left.\begin{array}{l}\text { CIC-positive, } 1 / 9 \\ \text { CIC-negative, } 7 / 12\end{array}\right\} \mathrm{p}=0 \cdot 028$

Non-Behçet’s+severe RV:

$\left.\begin{array}{l}\text { AB-positive, } 4 / 29 \\ \text { AB-negative, }(0 / 12\end{array}\right\} p=0 \cdot 18$

Mean disease scores of AB-positive patients:

CIC-positive $(n=26), 10 \cdot 0($ SEM $1 \cdot 7)\}, p=0 \cdot 1$

RV+SID patients $17(22 \%)$ had severe retinal disease. Table 5 shows that seven of the eight patients with Behçet's disease and severe RV had antiretinal antibodies in the absence of circulating immune complexes $(p=0.028)$; that in patients without Behçet's disease (41) the few patients with severe retinal disease (DS $>20$ points) were all antibodypositive (4/29), while none of 12 antibody-negative patients had severe retinal disease. In the RV+SID category as a whole there was a tendency for antibody-positive patients without raised CIC to have higher retinal disease scores than those with raised CIC levels ( $p=0 \cdot 1$, Table 5). Thus in the RV+ SID category there was evidence that certain patients with antiretinal autoimmunity and absent circulating immune complexes had severe retinal disease.

Of the 63 patients with RV alone only eight (13\%) had severe retinal disease (DS $>20$ points), though the mean disease score of the 63 patients (11.6 (SEM 4.0)) was similar to that of the 78 patients with RV+ SID (mean: 11.5 (SEM 3.8)). In the 33 patients with RV alone who were antibody-positive (Table 2) there was no significant difference between the mean disease score of the 14 who were CIC-positive (14.5

Table 6 Association between principal features of retinal vasculitis and the prevalence of immunological abnormalities

\begin{tabular}{|c|c|c|c|c|}
\hline \multirow{2}{*}{$\begin{array}{l}\text { Features of retinal vasculitis } \\
\text { (patient numbers) }\end{array}$} & \multicolumn{2}{|c|}{$\begin{array}{l}\text { Prevalence of circulating } \\
\text { immune complexes }\end{array}$} & \multicolumn{2}{|c|}{$\begin{array}{l}\text { Prevalence of antiretinal } \\
\text { antibodies }\end{array}$} \\
\hline & Total & $\begin{array}{l}\text { Proportion with } \\
\text { antiretinal } \\
\text { antibodies }\end{array}$ & Total & $\begin{array}{l}\text { Proportion with } \\
\text { circulating immune } \\
\text { complexes }\end{array}$ \\
\hline \multicolumn{5}{|l|}{ Macular oedema } \\
\hline Present (80) & $25 / 80 *$ & $18 / 25$ & $50 / 80$ & $18 / 50 \dagger$ \\
\hline Absent (62) & $31 / 62^{*}$ & $20 / 31$ & $33 / 62$ & $20 / 33+$ \\
\hline \multicolumn{5}{|c|}{ Periphlebitis or perivascular sheathing } \\
\hline Present (98) & $39 / 98$ & $25 / 39$ & $59 / 98$ & $25 / 59$ \\
\hline Absent (44) & $17 / 44$ & $13 / 17$ & $24 / 44$ & $13 / 24$ \\
\hline \multicolumn{5}{|c|}{ Capillary closure or capillary leakage } \\
\hline Present (87) & $30 / 87$ & $19 / 30$ & $49 / 87$ & $19 / 49 \ddagger$ \\
\hline Absent (55) & $26 / 55$ & $19 / 26$ & $34 / 55$ & $19 / 34 \ddagger$ \\
\hline \multicolumn{5}{|l|}{ Vein occlusions or new vessels } \\
\hline Present (40) & $11 / 40$ & $8 / 11$ & $23 / 40$ & $8 / 23$ \\
\hline Absent (102) & $45 / 102$ & $30 / 45$ & $60 / 102$ & $30 / 60$ \\
\hline
\end{tabular}

${ }^{*} p=0 \cdot 023 .+p=0 \cdot(28 . \ddagger p=0 \cdot 13$. 
points) and the 19 who were CIC-negative (12.4 points). Unlike the RV+SID category (see above), there was no subgroup of patients with $\mathrm{RV}$ alone that had an apparent 'syndrome' of antiretinal autoimmunity, absent circulating immune complexes, and severe retinal disease.

ASSOCIATION OF IMMUNOLOGICAL ABNORMALITIES WITH FEATURES OF RETINAL VASCULITIS

Table 6 displays the prevalence of circulating immune complexes and antiretinal antibodies in relation to four principal features of retinal vasculitis in the whole series of patients, and it shows that there was a tendency for the individual features to be associated with antiretinal antibodies unaccompanied by circulating immune complexes.

Macular oedema. More than half $(56 \%)$ of all the patients in the study had evidence of macular oedema. Antiretinal antibodies were found more frequently in patients with macular oedema $(63 \%)$ than in those who had a normal macula $(53 \%)$, though the difference was not statistically significant. However, as shown in Table 6 , there was a significantly lower incidence of raised CIC in patients with macular oedema in comparison with those with normal macula $(p=0.023)$; and antiretinal antibodies were less frequently accompanied by CIC in these patients $(\mathrm{p}=0.028$ : see Table 6).

Periphlebitis and perivascular sheathing. Ninetyeight patients $(69 \%)$ had one or both of these two clinical features. Of these patients $59 \%$ had antiretinal antibodies and $39 \%$ had raised CIC levels. The prevalence of these immunological features was the same as in the total population of 142 patients studied (see Table 2). There was a tendency for a higher frequency of CIC unaccompanied by retinal antibodies in the sera of patients with perivascular sheathing or periphlebitis $(35 \%)$ in comparison with those without (22\%).

Capillary closure and/or leakage. Eighty-seven patients $(61 \%)$ had evidence of capillary closure or leakage as judged by fluorescein angiography. The prevalence of antiretinal antibodies $(58 \%)$ and CIC (23\%) in patients with these clinical features was not dissimilar to that in the total population of patients studied. There was a tendency for patients with capillary closure or leakage to have a higher frequency of antiretinal antibodies in the absence of CIC $(61 \%)$ in their sera in comparison with those who did not have these retinal features $(44 \%)$, where antiretinal antibodies tended to be more associated with CIC.

Vein occlusion or new vessels. These two clinical features were found in 40 patients only. The prevalence of antiretinal antibodies in the sera of these patients $(59 \%)$ was the same as in the whole popula- tion studied, but raised CIC levels tended to occur less frequently $(28 \%)$ in patients with vein occlusion or new vessels than in patients without these features $(45 \%: p=0 \cdot 068)$. The majority $(65 \%)$ of antiretinal antibodies in the sera of patients with vein occlusion or new vessels were unaccompanied by raised levels of CIC, while antiretinal antibodies in patients without these features were equally distributed between $\mathrm{CIC}$-positive and $\mathrm{CIC}$-negative sera.

\section{Discussion}

In this paper we report on the prevalence of antiretinal antibodies and circulating immune complexes in 63 patients with isolated retinal vasculitis and 79 patients with retinal vasculitis accompanying systemic inflammatory diseases-data obtainable on 142 of the 150 patients whose clinical and ophthalmological features are described in the preceding paper. ${ }^{3}$ In extending our earlier work ${ }^{6}$ we undertook this much larger study to determine whether patients with isolated retinal vasculitis (RV alone) would have a different immunological profile from those with retinal vasculitis accompanying systemic inflammatory disease (RV+SID) and to determine whether these immunological features would reflect the nature of associated systemic disease or the form and severity of retinal inflammation.

There have been a few reports concerning the presence of antiretinal antibodies in uveitis syndromes and these have stimulated some controversy. ${ }^{78}{ }^{10}$ Thus in 1981 Gregerson's group ${ }^{8}$ reported a $60 \%$ prevalence of antibody to retinal S-antigen in a series of patients with a wide spectrum of uveitis; this finding was recently challenged by Doekes et al ${ }^{5}$ who used a similar immunochemical technique (ELISA) but could not discriminate between uveitis patients and normal controls, both of whom had the same prevalence $(28-30 \%)$ of antibody to S-antigen. This study confirms our previous finding that both by immunofluorescence and passive haemagglutination antiretinal antibodies can be detected readily in patients with idiopathic retinal vasculitis ${ }^{6}$ and reports that their prevalence in retinal vasculitis $(58 \%)$ far exceeds that in normal individuals $(3 \cdot 5 \%)$.

It is likely that the prevalence of immunological abnormalities in uveitis syndromes depends both on the technique of detection and the clinical criteria on which the patient population is defined. Our previous finding of circulating immune complexes (CIC) in retinal vasculitis ${ }^{6}$ was in accord with the findings of Char $\mathrm{et} \mathrm{al}^{4}$ on uveitis sera, and the prevalence of CIC in the present study $(40 \%)$ provides further confirmation of this. We have accordingly proceeded to identify associations between the prevalence of antiretinal antibodies and circulating immune complexes 
in this larger series of patients with well characterised retinal vasculitis, ${ }^{3}$ with particular reference to the clinical interpretation of these immunological abnormalities.

In the present study a majority of the circulating immune complexes (CIC) were complement (Clq)binding and very few sera were positive by both the Clq and PEG tests (Table 1). In all groups of patients the proportion of sera reactive only for antiretinal antibodies was greater than the proportion of sera reactive only for CIC (Fig. 2), suggesting the greater relevance of autoimmune rather than immunecomplex mediated pathogenetic mechanisms. However, antiretinal antibodies tended to be more prevalent in CIC-positive sera $(p=0.066$, Table 3$)$; and, while this association was dominated by the RV+SID category $(p=0.036$, Table 3$)$, it was a particular feature of patients with systemic diseases other than Behçet's disease and sarcoid (Table 2). In terms of the mere prevalence of these immunological abnormalities patients with retinal vasculitis accompanying Behçet's disease appeared to resemble those with isolated retinal vasculitis more closely than those with other systemic inflammatory diseases (Table 2). Further immunochemical investigationof the size and composition of the immune complexes and of the isotype and complement-fixing ability of the antiretinal antibodies - would clarify whether the qualitative nature of these immunological reactants could be of additional clinical significance.

When retinal disease score was also considered, the two major patient categories showed different patterns of association between the prevalence of antiretinal antibodies, CIC, and severity of retinal disease. Patients with RV alone, of disease score greater than 10 points, had a significantly higher prevalence of antiretinal antibodies than those with a lower disease score, while there was no such difference in the RV+SID category as a whole (Table 4). The findings that, in $\mathrm{RV}$ alone, antiretinal antibodies were preferentially associated with CIC positivity in patients with the higher disease scores (Table 4) suggests that both antiretinal autoimmunity and circulating immune complex formation contribute to the pathogenesis of isolated retinal vasculitis. In terms of disease severity there appeared to be an additive effect of antiretinal antibodies and CIC together in RV alone, where patients with both immunological abnormalities had significantly more severe retinal disease than those with $\mathrm{CIC}$ only $(p=0 \cdot 010$, Fig. 3). In contrast, the combination of both features in patients with RV+SID had no additive effect ( $p=0 \cdot 014$, Fig. 3$)$.

Further analysis revealed that in $R V+S I D$, patients who were positive for both antiretinal antibodies and CIC tended to have the lower mean retinal disease scores (Table 5); and that in all three groups (RV+Behçet's disease, RV+sarcoid, RV+ other SIDs) those with antiretinal antibodies had higher mean disease scores if they were CICnegative. This was particularly true of the Behçet's disease group, where those who were antibodypositive, CIC-negative, had the highest prevalence of severe retinal vasculitis, with disease scores greater than 20 points $(p=0.028$, Table 5). These findings reinforce our earlier proposition that, in certain patients with retinal vasculitis, $\mathrm{CIC}$ formation may indicate the operation of a protective (? anti-idiotypic) host response to antiretinal autoimmunity," while in other patients CIC formation may add to the pathogenetic impact of autoimmunity on the retina.

The clinical relevance of studying antiretinal autoimmunity and circulating immune complexes in patients with retinal vasculitis would therefore appear to depend on the form of associated systemic disease and on the nature and occurrence of those features of retinal inflammation which contribute to disease severity in the individual patient. In isolated retinal vasculitis it seems that antiretinal antibodies are associated particularly with macular oedema and that the concomitant presence of circulating immune complexes and antiretinal antibodies is associated with more severe disease characterised in addition by perivascular sheathing and diffuse capillary leakage. In retinal vasculitis accompanying systemic inflammatory disease the most severely affected patients are antibody-positive despite anti-inflammatory and immunosupressive drug treatment. In Behçet's disease antiretinal antibodies may be absent; but, if they are present, the severely affected patient tends to be CIC-negative. Study of a larger group of RV patients with Behçet's disease would be required to determine whether retinal infiltrates, branch vein retinal occlusion and neovascularisation, macular oedema, and diffuse capillary leakage in this condition are specifically associated with one or other immunological profile. In RV accompanying sarcoidosis the most severely affected patients also have antiretinal antibodies unaccompanied by CIC. This finding suggests that periphlebitis and focal vascular leakage in retinal sarcoidosis have an autoimmune rather than an immune-complex pathogenesis. RV patients with other systemic inflammatory diseases, including the uveomeningitic syndrome, tended to have lower disease scores than patients with Behçet's disease or sarcoidosis; however, the most severely affected patients in this additional group were also those who had antiretinal antibodies in the absence of circulating immune complexes.

We conclude that the ophthalmological significance of studying antiretinal autoimmunity and non-tissuc- 
specific immunological abnormalities in retinal vasculitis may prove to be of diagnostic, prognostic, and pathogenetic value. In diagnostic and prognostic terms the identification of antiretinal autoimmunity may single out those patients at risk of more severe retinal disease or its more frequent relapse. ${ }^{14}$ In pathogenetic terms it appears that antiretinal autoimmunity is important in both isolated retinal vasculitis and retinal vasculitis accompanying certain systemic inflammatory diseases. However, the presence of raised levels of circulating immune complexes appears to confer an additional pathogenetic component in isolated $\mathrm{RV}$ while appearing to modulate retinal disease severity in the systemic syndromes. The central problem underlying this field concerns an understanding of how antiretinal autoimmunity is regulated and how its pathogenetic impact on the retina is brought about. Our continued study of defined groups of patients with autoimmune retinal vasculitis is aimed at clarifying this intriguing question.

\section{References}

1 Elschnig A. Studeien zur sympathischen Ophthalmis. Die antigene Wirkung des Augenpigmentes. Graefes Arch Clin Exp Ophthalmol 1910; 76: 509-46.

2 Sanders MD. Duke-Elder lecture. Retinal arteritis, retinal vasculitis and autoimmune retinal vasculitis. Eye 1987; 1: 441-65.

3 Graham EM, Stanford MR, Sanders MD, Kasp E, Dumonde DC. A point prevalence study of 150 patients with idiopathic retinal vasculitis: I. Diagnostic value of ophthalmological features. Br J Ophthalmol 1989: 73: 714-21.
4 Char DH, Stein P, Masi R, Christensen M. Immune complexes in uveitis. Am J Ophthalmol 1979: 87: 678-81.

5 Doekes G, van der Gaag R, Rothova A, et al. Humoral and cellular immune responsiveness to human $\mathrm{S}$-antigen in uveitis. Curr Eye Res 1987; 6: 909-19.

6 Dumonde DC, Kasp-Grochowska E, et al. Anti-retinal autoimmunity and circulating immune complexes in patients with retinal vasculitis. Lancet 1982 ; ii: 787-92.

7 Faure JP, de Kozak Y. Cellular and humoral reactions to retinal antigen; specific suppression of experimental uveoretinitis. In: Helmsen RJ, Suran A, Gery I, Nussenblatt RB, eds. Immunology of the eye. II. National Institutes of Health Workshop on autoimmune phenomena and ocular disorders. Washington: Information Retrieval Inc, 1981: 33-48.

8 Gregerson DS, Abrahams IW. Thirkill CE. Serum antibody levels of uveitis patients to bovine retinal antigens. Invest Ophthalmol Vis Sci 1981; 21: 669-80.

9 Nussenblatt RB, Gery I, Ballintine EJ, Wacker WB. Cellular immune responsiveness of uveitis patients to retinal S-antigen. Am J Ophthalmol 1980; 89: 173-9.

10 Chan CC, Palestine AG, Nussenblatt RB, Roberge FG, Benezra D. Anti-retinal auto-antibodies in Vogt-Koyanagi-Harada syndrome, Behçet's disease and sympathetic ophthalmia. Ophthalmology 1985; 92: 1025-8.

11 Kasp E, Banga JP, Brown EC, et al. An improved method for the purification of retinal S-antigen using selective hydrophobic adsorption chromatography. J Immunol Methods 1987: 100: 147-52.

12 Poulton TA, Crowther ME, Hay FC, Nineham LJ. Immune complexes in ovarian cancer. Lancet 1978: i: 72-3.

13 Hay FC, Nineham LJ, Roitt IM. Routine assay for the detection of immune complexes of known immunoglobulin class using solid phase Clq. Clin Exp Immunol 1976: 24: 396-400.

14 Stanford MR, Graham E, Kasp E, Sanders MD, Dumonde DC. A longitudinal study of clinical and immunological findings in 52 patients with relapsing retinal vasculitis. Br J Ophthalmol 1988: 72: $442-7$.

Accepted for publication 10 March 1989. 